\title{
Potential promoted productivity and spatial patterns of medium- and low-yield cropland land in China
}

\author{
YAN Huimin ${ }^{1}$, JI Yongzan ${ }^{1,2}$, LIU Jiyuan ${ }^{1}$, LIU Fang ${ }^{1}$, HU Yunfeng ${ }^{1}$, \\ KUANG Wenhui ${ }^{1}$ \\ 1. Institute of Geographic Sciences and Natural Resources Research, CAS, Beijing 100101, China; \\ 2. University of Chinese Academy of Sciences, Beijing 100049, China
}

\begin{abstract}
With a continuously increasing population and better food consumption levels, improving the efficiency of arable land use and increasing its productivity have become fundamental strategies to meet the growing food security needs in China. A spatial distribution map of medium- and low-yield cropland is necessary to implement plans for cropland improvement. In this study, we developed a new method to identify high-, medium-, and low-yield cropland from Moderate Resolution Imaging Spectroradiometer (MODIS) data at a spatial resolution of $500 \mathrm{~m}$. The method could be used to reflect the regional heterogeneity of cropland productivity because the classification standard was based on the regionalization of cropping systems in China. The results showed that the proportion of high-, medium-, and low-yield cropland in China was $21 \%, 39 \%$, and $40 \%$, respectively. About $75 \%$ of the low-yield cropland was located in hilly and mountainous areas, and about $53 \%$ of the high-yield cropland was located in plain areas. The five provinces with the largest area of high-yield cropland were all located in the Huang-Huai-Hai region, and the area amounted to $42 \%$ of the national high-yield cropland area. Meanwhile, the proportion of high-yield cropland was lower than $15 \%$ in Heilongjiang, Sichuan, and Inner Mongolia, which had the largest area allocated to cropland in China. If all the medium-yield cropland could be improved to the productive level of high-yield cropland and the low-yield cropland could be improved to the level of medium-yield cropland, the total productivity of the land would increase $19 \%$ and $24 \%$, respectively.
\end{abstract}

Keywords: food security; light use efficiency model; cropland productivity; high-, medium- and low-yield cropland; potential productivity

\section{Introduction}

Continuous population growth and food consumption have placed huge pressure on agriculture and natural resources, and greatly increased food production is needed to ensure global food security (Foley et al., 2011). Grain production in most arable land is far below the po-

Received: 2015-06-09 Accepted: 2015-08-20

Foundation: STS Project of CAS, No.KFJ-EW-STS-001; National Natural Science Foundation of China, No.41430861

Author: Yan Huimin, PhD, specialized in land use change. E-mail: yanhm@igsnrr.ac.cn 
tential productivity of high-producing cropland under similar climatic conditions (Foley et al., 2011; Tilman et al., 2011). There is therefore great potential to improve the actual productivity and the land use efficiency of arable land. A substantial rise in food production can be achieved through the adoption of new technologies, improved water and nutrient-use efficiency, and advanced agricultural management (Foley et al., 2011; Foley et al., 2005; Shi et al., 2010; Tilman et al., 2011; Zhang et al., 2005). China is the world's largest producer and consumer of agricultural products, and is faced with increasing resource constraints to agricultural development (Shi et al., 2010). The sustained and steady growth of agriculture in China will have to rely on an acceleration of agricultural science and technological innovation that will improve the efficiency of resource utilization ${ }^{1)}$ and result in efficient, high-yielding agriculture coordinated with sustainable resource use.

To improve the basic conditions for agricultural production, the Chinese government initiated a medium- and low-yield cropland improvement project in 1988, and a high-standard cropland construction project in 2009. From 1988 to 2012, approximately 661 million hectares (ha) of cropland ${ }^{2}$ in 2045 counties and 222 state-owned farms were covered by these types of projects. In 2013, the State Council of the People's Republic of China approved the "National Comprehensive Agricultural Development and High-standard Farmland Construction Plan" with a goal of 800 million $\mathrm{mu}(15 \mathrm{mu}=1 \mathrm{ha})$ of high-standard cropland and improved medium- and low-yield cropland by 2020 . Therefore, an accurate and explicit spatial expression of medium- and low-yield cropland distribution is necessary before implementing a cropland promotion plan.

Current studies show that high-, medium-, and low-yield cropland can be identified using the following three methods. The first one is the cropland quality method based on field survey data. This method classifies cropland into quality levels using obstacle factors as key indicators. High-yield cropland has few limitations, and classification of medium- and low-yield cropland is conducted according to different limitation levels (Lin, 2008). The second one is the average yield method based on statistical data (Lin, 2008; Wu, 2009). A certain deviation (e.g., $15 \%$ or $50 \mathrm{~kg}$ ) from the average yield is taken as the upper or lower limit of medium-yield cropland. The third one is the potential productivity method (Lin, 2008), in which classification of high-, medium-, and low-yield cropland is conducted according to the ratio values of their actual productivity to potential productivity. These methods have both advantages and disadvantages. The cropland quality method requires systematic and detailed fieldwork to evaluate the limiting factors of cropland; it is labor intensive, requires capital investment, and is time consuming, and it is difficult for near real-time monitoring and evaluation of cropland quality on a large scale. The average yield method is hard to avoid the interference of cropping system adjustments and crop variety changes. In addition, county-based statistical data is important for qualifying the actual productivity of cropland at a national or regional scale; however, it cannot evaluate the quality of specific plots. The potential productivity method needs an estimation of the maximum potential productivity of cropland and involves complex computational processes. Therefore, a novel method for spatially explicit monitoring and effective evaluation of cropland quality on a

1) Chen Xiwen: stick to the path of agricultural modernization with Chinese characteristics, http://cpc.people.com.cn/ GB/64162/82819/114926/114927/6840448.html (2008/01/30)

2) Wang Guangkun: http://www.farmer.com.cn/xwpd/btxw/201312/t20131206_920451.htm (2013/12/06) 
large scale is needed to improve the sustainable use of arable land.

The development of satellite observation techniques provides data access for land use change and the monitoring of crop growth for different spatial-temporal scales (Li Folin, 2005). The development of productivity models makes them increasingly applicable to the simulation of the productivity of various ecosystems and their responses to climate and land use changes at multiple scales (Huang et al., 2008; Li Folin, 2005; Wang et al., 2010; Yan et al., 2012). Large developments in remote sensing technology and remote sensing models for cropland productivity make it feasible to propose a novel classification method of high-, medium-, and low-yield cropland. Ecosystem net primary productivity (NPP) represents the accumulated organic matter of plants per unit area and time. It directly represents cropland actual productivity and provides a unified measurement for the productivity of various crops. Remote sensing based NPP estimation has become an effective and feasible metric to monitor high-, medium-, and low-yield cropland. The VPM (Vegetation Photosynthesis Model) is one of the important methods for estimating NPP based on MODIS data. The VPM can estimate ecosystem productivity in regions with multiple cropping systems (Yan et al., 2012; Yan et al., 2009). In this study, we simulated cropland NPP using a VPM model and MODIS data with a spatial resolution of $500 \mathrm{~m}$. We then identified high-, medium-, and low-yield cropland according to the derived standard in each cropping system zone of China. We finally estimated the level of potential productivity of medium- and low-yield cropland.

\section{Data and methods}

\subsection{The VPM model}

The VPM (Xiao et al., 2004) is a satellite-based light use efficiency model used in estimating ecosystem productivity. The model has been validated by $\mathrm{CO}_{2}$ flux observation data in different cropland ecosystems, including spring corn (Wang et al., 2010) in northeast China and a winter wheat-summer maize rotation in Yucheng (Yan et al., 2009).

In the VPM, gross primary productivity (GPP) is estimated based on Monteith's equation; estimation of GPP is expressed as:

$$
G P P=\varepsilon_{g} \times F P A R_{c h l} \times P A R
$$

where $\varepsilon_{g}$ is the light use efficiency ( $\mu \mathrm{mol} \mathrm{CO}_{2} / \mu \mathrm{mol}$ PPFD), FPAR $R_{c h l}$ is the fraction of photosynthetically active radiation (PAR) absorbed by leaf chlorophyll in the canopy, and PAR is the photosynthetically active radiation ( $\mu$ mol photosynthetic photon flux density, PPFD).

Light use efficiency $\left(\varepsilon_{g}\right)$ is affected by temperature, water, and leaf phenology:

$$
\varepsilon_{g}=\varepsilon_{0} \times T_{\text {scalar }} \times W_{\text {scalar }} \times P_{\text {scalar }}
$$

where $\varepsilon_{0}$ is the maximum radiation use efficiency ( $\mu \mathrm{mol} \mathrm{CO}_{2} / \mu \mathrm{mol} \mathrm{PAR}$ ). The value of $\varepsilon_{0}$ was calculated from NEE (Net Ecosystem Exchange) and incident PAR observed from $\mathrm{CO}_{2}$ eddy flux tower sites (Yan et al., 2012). $T_{\text {scalar }}, W_{\text {scalar }}$, and $P_{\text {scalar }}$ are the scalars for the effects of temperature, water, and leaf phenology on the light use efficiency of vegetation, respectively. More detailed methods for calculating the parameters above have been reported by Kalfas et al. (2011).

NPP is estimated as the ratio of autotrophic respiration to GPP. According to the experimental results of respiration rate on wheat, sunflower, sorghum, and beans, the ratio value of autotrophic respiration to GPP generally remains constant and equal to 0.42 (Albrizio et al., 
2003; Ball, 1996; Cheng et al., 2000; Gifford, 1995).

\subsection{Data}

(1) Cropland distribution

Cropland distribution data came from the National Land-Use/Land-Cover Dataset (NLCD) with a mapping scale of 1:100 000. The dataset was interpreted from Landsat TM/ETM images with a $30-\mathrm{m}$ spatial resolution and its accuracy was validated by extensive field survey data.

(2) Cropland productivity

National cropland NPP during 2000-2008 was simulated using a VPM model. In order to eliminate effects from climate fluctuation and agricultural management changes, the average NPP of 2001-2010 was taken as the cropland productivity for high-, medium-, and low-yield cropland classification.

(3) Cropping system zones of China

To take into account the regional differences in natural and climatic conditions, a map of China's cropping system zones was used in this study. China's arable land is divided into three cropping zones, 12 major zones, and 38 sub-zones in terms of heat, water, topography, cropping systems, crop types, and socio-economic conditions (Figure 1). Within each cropping sub-zone, a standard for high-, medium-, and low-yield cropland classification was developed in this study.

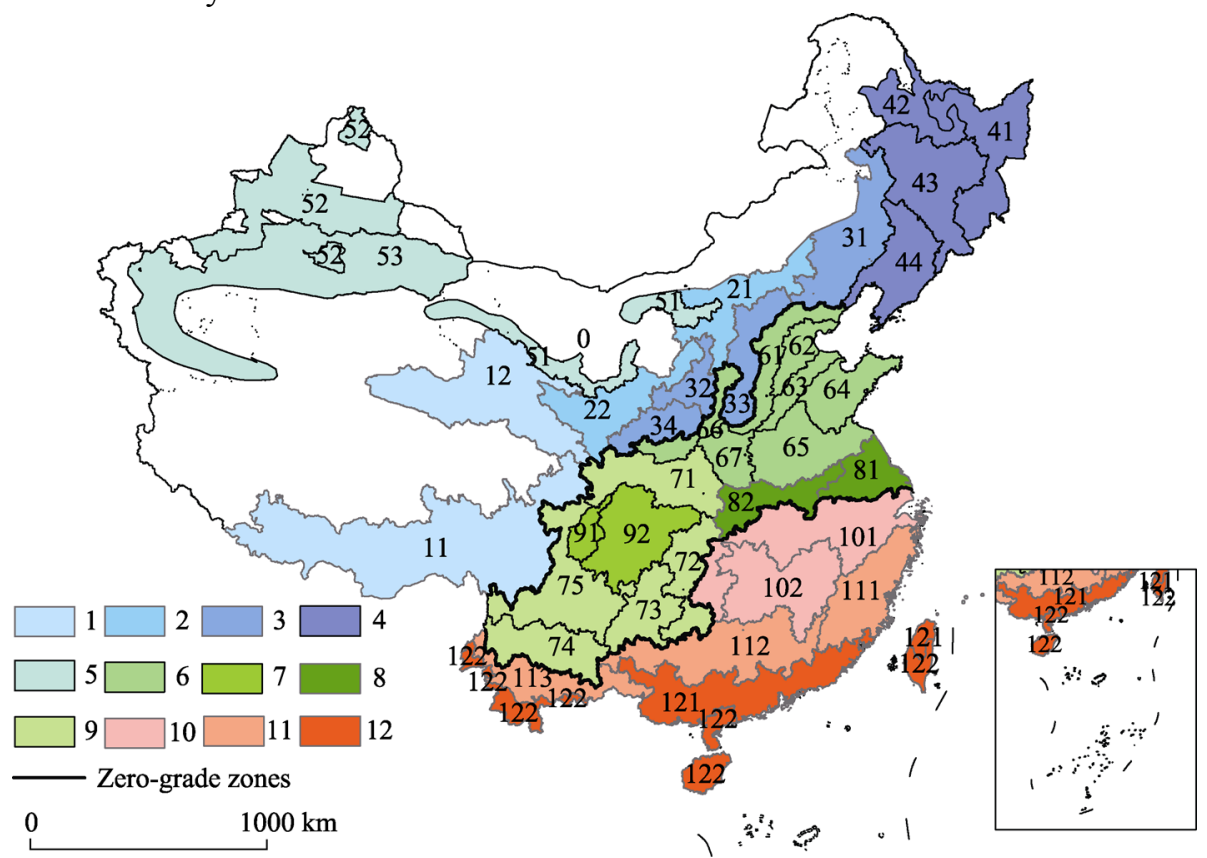

Figure 1 Map of China's cropping system zones. The zero-grade zones classify the land as single-, double-, and triple-cropping zones. The numbers, ranging from 1 to 12 , represent the codes of major zones and are marked in the same color. Thirty-eight sub-zones are labeled by numbers.

The driving data for the VPM model included the Enhanced Vegetation Index (EVI) and Land Surface Water Index (LSWI), temperature and PAR, in which EVI and LSWI were calculated from MODIS surface reflectance product (MOD09A1, http://www.edc.usgs.gov/) 
with $500 \mathrm{~m}$ spatial and 8-day temporal resolution. Temperature data was derived from meteorological observations provided by the China Meteorological Data Sharing Service System (http://www.cma.gov.cn/2011qxfw/2011qsjgx/). PAR data was retrieved from MODIS surface reflectance product.

\subsection{High-, medium-, and low-yield cropland classification method}

In this study, medium-, and low-yield cropland indicated the cropland with a lower or much lower productivity output than their potential under the current natural and socio-economic conditions. High-yield cropland referred to highly productive cropland with few limiting factors to its agricultural production.

To avoid misclassification caused by mixed pixels, we chose pixels with a cropland area percentage of not less than $50 \%$ within each $500 \mathrm{~m}$ x $500 \mathrm{~m}$ grid for the classification criteria, and obtained frequency distribution histograms of NPP in different agricultural regions. There were four typical frequency distribution histograms in 38 sub-zones (Figure 2), and each of them had a concentrated distribution. The NPP values at two inflection points before and after the concentrated distribution were regarded as the boundary values, and the grids outside the intervals with low frequency were taken as noise. $\mathrm{NPP}_{\mathrm{a}}$ and $\mathrm{NPP}_{\mathrm{b}}$ represented two inflection points $\left(\mathrm{NPP}_{\mathrm{a}}<\mathrm{NPP}_{\mathrm{b}}\right)$; $\mathrm{NPP}_{\text {dif }}$ was defined as the difference between $\mathrm{NPP}_{\mathrm{b}}$ and $\mathrm{NPP}_{\mathrm{a}}$. Theoretically, the proportion of high-, medium-, and low-yield cropland area should be the same, which means $\mathrm{NPP}_{\mathrm{a}}+1 / 3 * \mathrm{NPP}_{\text {dif }}$ should be the upper limit of low-yield cropland,
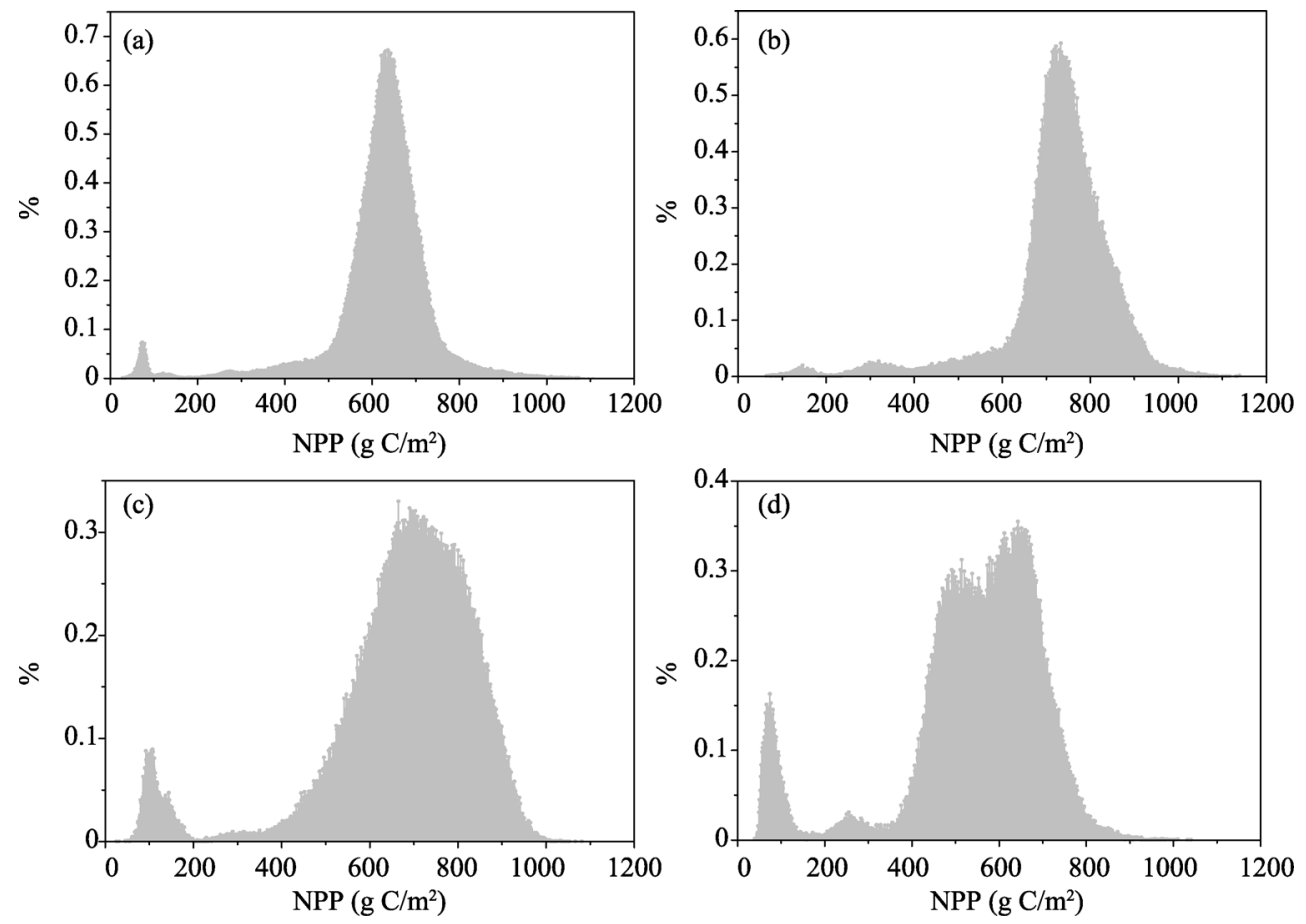

Figure 2 Four typical frequency distribution histograms 43-single cropping zone in Songnen Plain (a); 82-irrigated and dryland zone in Hubei-Henan-Anhui hilly plain (b); 61-irrigated double cropping and dryland single cropping in piedmont plain of Yanshan and Taihang Mountains (c); 33-semi-humid and drought-prone single cropping in east Shanxi Province (d) 
and $\mathrm{NPP}_{\mathrm{b}}-1 / 3 * \mathrm{NPP}_{\text {dif }}$ should be the lower limit of high-yield cropland. However, considering the continuous cropland improvement projects in recent years, the proportions for the three types of cropland were adjusted to $30 \%, 35 \%$, and $35 \%$, respectively. The boundaries for high-, medium-, and low-yield cropland are expressed as follows:

Upper limit for low-yield cropland $=\mathrm{NPP}_{\mathrm{a}}+\mathrm{NPP}_{\mathrm{dif}} * 30 \%$

Lower limit for high-yield cropland $=\mathrm{NPP}_{\mathrm{b}}-\mathrm{NPP}_{\text {dif }} * 35 \%$

\section{Results}

\subsection{Spatial patterns of high-, medium-, and low-yield cropland}

The proportional areas of high-, medium-, and low-yield cropland in China were approximately $20.66 \%, 39.56 \%$ and $39.78 \%$, respectively. High-yield cropland is mainly distributed in the North China Plain, the middle and lower reaches of the Yangtze River Plain, Sichuan Basin, central Jilin, and northeastern Liaoning. These regions provide the best conditions for crop growth with flat terrain and abundant water resources. A small amount of high-yield cropland is distributed in central Shaanxi, northern Ningxia, central and southern Gansu, and northwestern Xinjiang. Although these regions have a relatively poor climate conditions, natural rivers ensure water supply and agricultural development, so they offer a greater productive potential than other cropland in the same agricultural region. Medium-yield cropland is mainly concentrated in the Northeast China Plain, Sichuan Basin, southern and central Henan, and northern Anhui, most of which are surrounding or close to high-yield cropland. Low-yield cropland is distributed in regions with poor natural geographic and climatic conditions, such as the Loess Plateau, the Yunnan-Guizhou Plateau, and the farming-pastoral ecotone of Inner Mongolia (Figure 3).

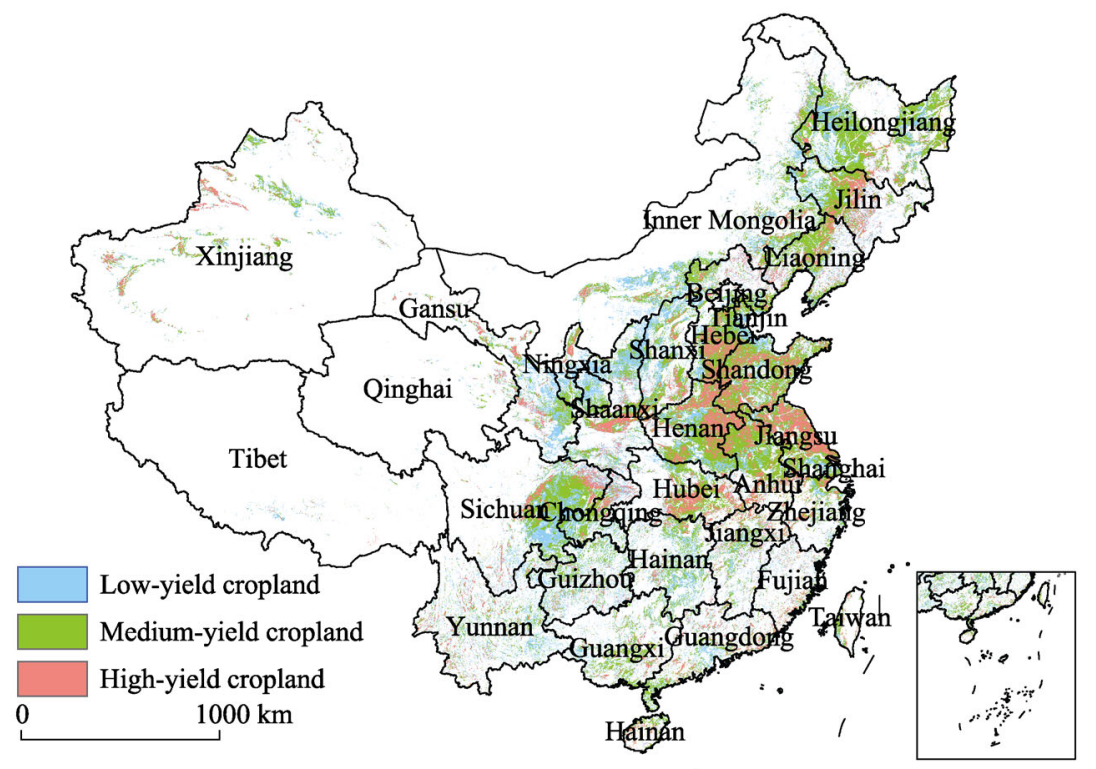

Figure 3 The distribution map of high-, medium-, and low-yield cropland in China

Besides temperature and water conditions, topography is an important factor causing regional differences in cropland productivity. In this study, degrees of relief were extracted 
from a 1-km digital elevation model (DEM) with an appropriate analysis window of $5 \mathrm{~km} \times$ $5 \mathrm{~km}$ (Zhang et al., 2012). The regions with a relief degree lower than $30 \mathrm{~m}$ were defined as plain areas and regions with a relief degree higher than $30 \mathrm{~m}$ were defined as hilly and mountainous areas (Liu et al., 2001). In China, 40\% of cropland is located in plain areas, while $60 \%$ of cropland is located in hilly and mountainous areas. In the plain areas, medium-yield cropland accounted for $48.14 \%$, while high- and low-yield cropland accounted for $27.95 \%$ and $23.91 \%$, respectively. In the hilly and mountainous areas, low-yield cropland accounted for the largest area, being $49.15 \%$, and proportions of mediumand high-yield cropland were $34.61 \%$ and $16.24 \%$, respectively (Figure 4 ). In general, about $75 \%$ of low-yield cropland was located in the hills and mountains, and the area of medium-yield cropland distributed on the plains was similar to that of the hills and mountains, while proportions of high-yield cropland distributed on the plains and in the hilly and mountainous areas were 53\%

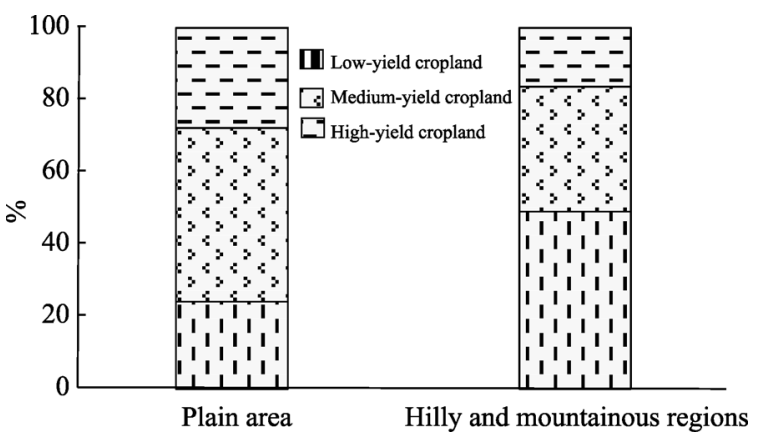

Figure 4 The composition of different terrain areas and croplands and $47 \%$, respectively.

The five provinces with the largest high-yield cropland areas were Henan, Shandong, Jiangsu, Hebei, and Anhui located in the Huang-Huai-Hai Plain region, followed by Hubei, Jilin, and Sichuan provinces. The spatial distribution of high-yield cropland in the above eight provinces was concentrated, and the sum of these high-yield areas accounted for $57.3 \%$ of the national high-yield cropland area. Medium- and low-yield cropland was mainly located in Heilongjiang, Sichuan, Inner Mongolia, Henan, and Hebei, accounting for 34.88\% of the national medium-, and low-yield cropland area. There were 12 provinces (autonomous regions) in which the proportion of high-yield cropland was greater than the national average $(20.66 \%)$; Jiangsu ranked first with approximately $50 \%$ of high-yield cropland. There were 17 provinces (autonomous regions and municipalities) with proportional areas of low-yield cropland greater than the national average (39.78\%; Figure 5).

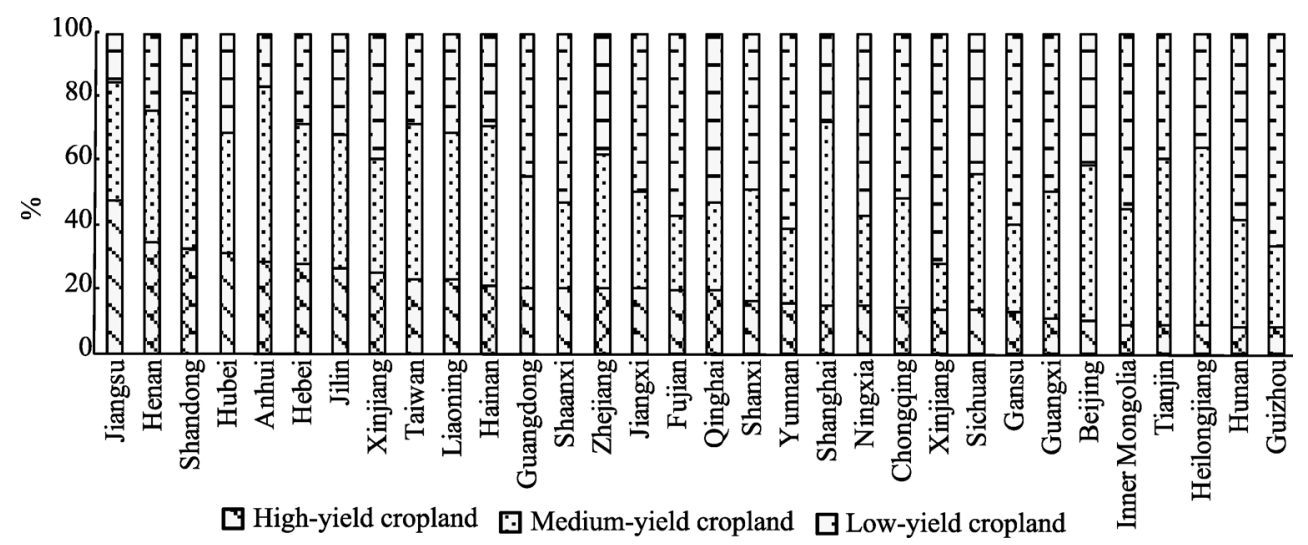

Figure 5 The proportions of high-, medium-, and low- yield cropland in each province 


\subsection{Potential promoted productivity of medium- and low-yield cropland}

Medium- and low-yield cropland refers to arable land that has a potential for increased productivity, because their current productivity levels are far below their potential productivity under the current natural and social conditions. The summed area of medium- and low-yield cropland accounted for $79.34 \%$ of the total cropland area in China. In this study, it was assumed that promoted medium- and low-yield cropland had the potential to reach new levels of productivity that may be as high as high-yield cropland in the same sub-zone of the cropping system zones. Therefore, the promoted potential of medium- and low-yield cropland productivity after reformation could be estimated according to the difference between the lower limit for high-yield cropland productivity and the upper limit for medium- or low-yield cropland productivity in each sub-zone. We suggest that low-yield cropland can reach medium-yield levels and that medium-yield cropland can reach high-yield levels, through the reformation of these arable lands. The average productivity of high-, medium-, and low-yield cropland in sub-zones is defined as $\mathrm{P}_{\text {high }}, \mathrm{P}_{\text {medium, }}$, and $\mathrm{P}_{\text {low }}$, respectively, while $\mathrm{P}_{\text {medium }}-\mathrm{P}_{\text {low }}$ and $\mathrm{P}_{\text {medium }}-\mathrm{P}_{\text {low }}$ represent the promoted potential for medium- and low- yield cropland productivity (Table 1 and Figure 6).

Table 1 Promoted potential of medium- and low-yield cropland productivity in sub-zones $\left(\mathrm{gC} / \mathrm{m}^{2} / \mathrm{a}\right)$

\begin{tabular}{|c|c|c|c|c|c|}
\hline $\begin{array}{l}\text { Sub-zone } \\
\text { code }\end{array}$ & $\begin{array}{l}\text { Promoted potential } \\
\text { of low-yield crop- } \\
\text { land productivity }\end{array}$ & $\begin{array}{l}\text { Promoted potential } \\
\text { of medium-yield } \\
\text { cropland productivity }\end{array}$ & $\begin{array}{l}\text { Sub-zone } \\
\text { code }\end{array}$ & $\begin{array}{l}\text { Promoted potential } \\
\text { of low-yield crop- } \\
\text { land productivity }\end{array}$ & $\begin{array}{l}\text { Promoted potential } \\
\text { of medium-yield } \\
\text { cropland productivity }\end{array}$ \\
\hline 11 & 167.53 & 214.61 & 65 & 135.99 & 91.91 \\
\hline 12 & 149.05 & 134.14 & 66 & 154.66 & 157.73 \\
\hline 21 & 80.97 & 115.43 & 67 & 91.62 & 87.16 \\
\hline 22 & 134.49 & 197.51 & 71 & 145.93 & 138.42 \\
\hline 31 & 120.70 & 129.34 & 72 & 128.45 & 101.59 \\
\hline 32 & 67.47 & 95.10 & 73 & 82.74 & 80.06 \\
\hline 33 & 122.54 & 122.51 & 74 & 269.63 & 241.69 \\
\hline 34 & 122.43 & 145.19 & 75 & 150.37 & 163.29 \\
\hline 41 & 89.15 & 97.85 & 81 & 190.49 & 135.47 \\
\hline 42 & 75.86 & 122.82 & 82 & 93.59 & 110.83 \\
\hline 43 & 84.80 & 80.20 & 91 & 79.49 & 72.63 \\
\hline 44 & 100.80 & 66.66 & 92 & 86.92 & 124.33 \\
\hline 51 & 238.04 & 195.18 & 101 & 174.25 & 178.35 \\
\hline 52 & 214.61 & 248.09 & 102 & 131.90 & 117.79 \\
\hline 53 & 225.30 & 190.01 & 111 & 197.00 & 248.66 \\
\hline 61 & 159.29 & 150.06 & 112 & 146.24 & 119.47 \\
\hline 62 & 126.33 & 120.05 & 113 & 247.75 & 266.32 \\
\hline 63 & 138.81 & 112.36 & 121 & 206.51 & 216.96 \\
\hline 64 & 147.89 & 117.72 & 122 & 297.01 & 321.38 \\
\hline
\end{tabular}

The productivity of medium- and low-yield cropland in China was $49,263.07 \times 10^{4} \mathrm{tC} / \mathrm{a}$ and $15,859.72 \times 10^{4} \mathrm{tC} / \mathrm{a}$. The promoted potential of medium- and low-yield cropland productivity was approximately $9318.65 \times 10^{4} \mathrm{tC} / \mathrm{a}$ and $3813.85 \times 10^{4} \mathrm{tC} / \mathrm{a}$, respectively. Thus, the productivity of medium- and low-yield cropland productivity would increase $18.92 \%$ and 
$24.05 \%$, respectively. The top five provinces with the highest promoted potential of low-yield cropland productivity were Yunnan, Sichuan, Heilongjiang, Inner Mongolia, and Guangdong; their promoted potential was higher than $200 \times 10^{4} \mathrm{tC} / \mathrm{a}$. The high promoted potential in Yunnan, Sichuan, and Inner Mongolia benefited from the large areas of low-yield cropland, while the high promoted potential of productivity per unit area in low-yield cropland was the main reason for the high potential promoted productivity in Guangdong (Table 2 and Figure 6).

Table 2 Production capability and potential promoted productivity of low-yield cropland in each province

\begin{tabular}{|c|c|c|c|c|c|c|}
\hline Province & $\begin{array}{l}\text { Area propor- } \\
\text { tion of } \\
\text { low-yield } \\
\text { cropland }(\%)\end{array}$ & $\begin{array}{l}\text { Low-yield } \\
\text { cropland } \\
\text { productivity } \\
\left(\times 10^{4} \mathrm{C}\right)\end{array}$ & $\begin{array}{c}\text { Proportion of } \\
\text { low-yield crop- } \\
\text { land productiv- } \\
\text { ity }(\%)\end{array}$ & $\begin{array}{l}\text { Potential } \\
\text { promoted } \\
\text { productivity } \\
\left(\times 10^{4} \mathrm{C}\right)\end{array}$ & $\begin{array}{c}\text { Increase } \\
\text { rate } \%\end{array}$ & $\begin{array}{l}\text { Proportion of } \\
\text { potential pro- } \\
\text { moted produc- } \\
\text { tivity (\%) }\end{array}$ \\
\hline Heilongjiang & 7.96 & 1732.78 & 10.93 & 258.18 & 14.90 & 6.77 \\
\hline Jilin & 3.29 & 452.45 & 2.85 & 88.00 & 19.45 & 2.31 \\
\hline Liaoning & 2.78 & 270.01 & 1.70 & 50.67 & 18.77 & 1.33 \\
\hline Beijing & 0.28 & 51.19 & 0.32 & 15.38 & 30.04 & 0.40 \\
\hline Tianjin & 0.38 & 90.19 & 0.57 & 21.86 & 24.24 & 0.57 \\
\hline Hebei & 3.85 & 662.04 & 4.17 & 173.34 & 26.18 & 4.55 \\
\hline Shandong & 2.70 & 440.02 & 2.77 & 108.70 & 24.70 & 2.85 \\
\hline Henan & 3.60 & 1021.36 & 6.44 & 175.70 & 17.20 & 4.61 \\
\hline Shanxi & 4.18 & 569.75 & 3.59 & 141.79 & 24.89 & 3.72 \\
\hline Shaanxi & 5.39 & 430.27 & 2.71 & 97.09 & 22.56 & 2.55 \\
\hline Gansu & 5.54 & 520.49 & 3.28 & 163.77 & 31.46 & 4.29 \\
\hline Xinjiang & 3.26 & 413.12 & 2.60 & 157.81 & 38.20 & 4.14 \\
\hline Inner Mongolia & 8.75 & 1008.00 & 6.36 & 235.99 & 23.41 & 6.19 \\
\hline Ningxia & 1.48 & 161.57 & 1.02 & 68.00 & 42.09 & 1.78 \\
\hline Qinghai & 0.61 & 22.78 & 0.14 & 9.06 & 39.80 & 0.24 \\
\hline Tibet & 0.46 & 19.03 & 0.12 & 10.77 & 56.60 & 0.28 \\
\hline Jiangsu & 1.42 & 337.51 & 2.13 & 102.14 & 30.26 & 2.68 \\
\hline Anhui & 1.85 & 476.93 & 3.01 & 104.79 & 21.97 & 2.75 \\
\hline Hubei & 2.89 & 376.33 & 2.37 & 86.22 & 22.91 & 2.26 \\
\hline Hunan & 4.98 & 699.15 & 4.41 & 174.32 & 24.93 & 4.57 \\
\hline Jiangxi & 3.09 & 532.08 & 3.35 & 114.66 & 21.55 & 3.01 \\
\hline Zhejiang & 1.48 & 480.30 & 3.03 & 154.58 & 32.18 & 4.05 \\
\hline Shanghai & 0.17 & 44.21 & 0.28 & 14.97 & 33.86 & 0.39 \\
\hline Guangdong & 2.75 & 679.24 & 4.28 & 231.58 & 34.09 & 6.07 \\
\hline Guangxi & 3.56 & 532.55 & 3.36 & 169.57 & 31.84 & 4.45 \\
\hline Fujian & 1.75 & 521.27 & 3.29 & 162.21 & 31.12 & 4.25 \\
\hline Hainan & 0.35 & 95.89 & 0.60 & 40.13 & 41.85 & 1.05 \\
\hline Taiwan & 0.26 & 78.64 & 0.50 & 31.66 & 40.26 & 0.83 \\
\hline Sichuan & 7.54 & 1772.73 & 11.18 & 265.77 & 14.99 & 6.97 \\
\hline Yunnan & 5.91 & 751.06 & 4.74 & 292.76 & 38.98 & 7.68 \\
\hline Chongqing & 2.79 & 468.50 & 2.95 & 64.14 & 13.69 & 1.68 \\
\hline Guizhou & 4.69 & 148.30 & 0.94 & 28.23 & 19.04 & 0.74 \\
\hline
\end{tabular}




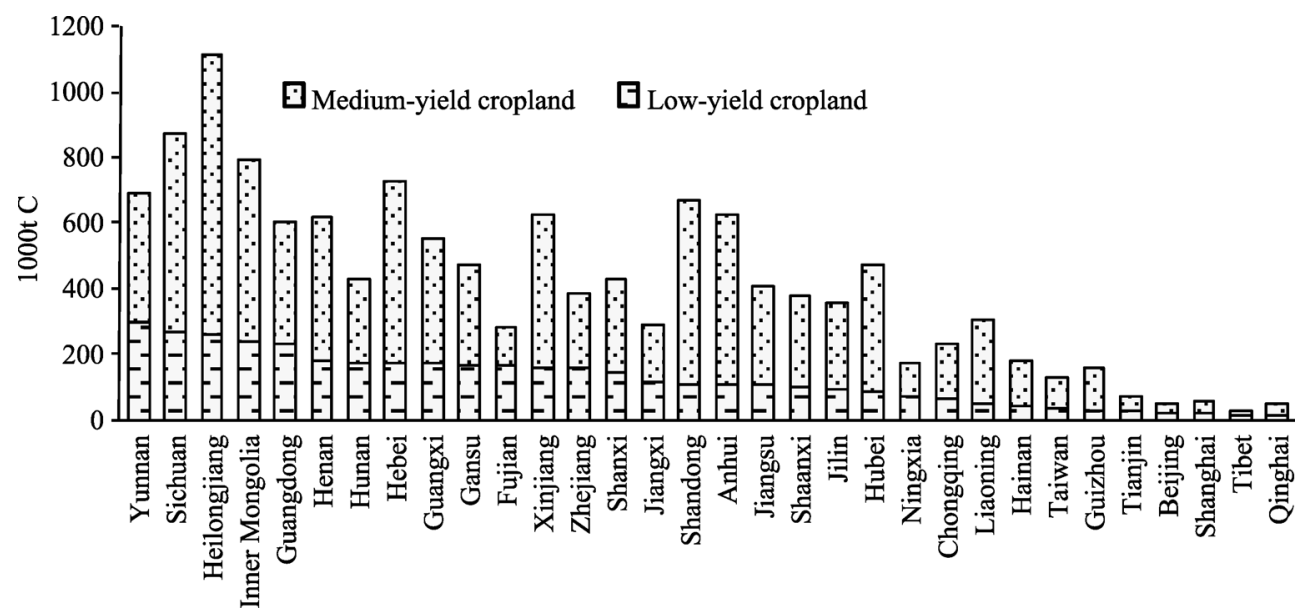

Figure 6 Potential promoted productivity in each province (ordered by total amount)

The top five provinces for promoted potential in medium-yield cropland were Heilongjiang, Sichuan, Shandong, Inner Mongolia, and Hebei, with a promoted potential above 550× $10^{4} \mathrm{tC} / \mathrm{a}$; Heilongjiang had the highest potential of approximately $851.49 \times 10^{4} \mathrm{tC} / \mathrm{a}$. The high potential in these five provinces was due to the large area of widely distributed medium-yield cropland, although the growth rates were all less than $25 \%$. The area and productivity of medium-yield cropland in Henan and Anhui were higher than those in Hebei and Inner Mongolia, but the promoted potential and growth rate were relatively low. The growth rate of promoted potential for medium-yield cropland was only $13.06 \%$ in Henan (Table 3 ).

The lowest five provinces with promoted potential of medium-yield cropland productivity were those regions with developed economies and small areas of cropland (Beijing, Tianjin, and Shanghai) or regions with poor natural conditions (Qinghai and Tibet). The promoted potential of low- and medium-yield cropland productivity in these regions was less than $25 \times 10^{4} \mathrm{tC} / \mathrm{a}$ and $50 \times 10^{4} \mathrm{tC} / \mathrm{a}$, respectively.

\section{Conclusions}

A spatial distribution map of medium- and low-yield cropland is necessary for planning cropland improvement and meeting the demand for food security in China. In this study, a spatial distribution map of high-, medium-, and low-yield cropland was developed from satellite observation data at a spatial resolution of $500 \mathrm{~m}$. Based on this map and the estimated actual cropland productivity, the potential productivity from promoting medium- and low-yield cropland was estimated. The results of this study showed that:

(1) The proportional areas of high-, medium-, and low-yield cropland in China were approximately $20.66 \%, 39.56 \%$, and $39.78 \%$, respectively. About $75 \%$ of low-yield cropland was located in the hilly and mountainous areas. In the plain areas, about $48 \%$ of the cropland was medium-yield, followed by high-yield cropland (28\%), and the low-yield area was similar to the high-yield area.

(2) Of China's medium- and low-yield cropland areas, more than $85 \%$ was distributed in Guizhou, Hunan, Heilongjiang, Tianjin, Inner Mongolia, Beijing, Guangxi, Gansu, Sichuan, Xinjiang, and Chongqing. Tibet, Guizhou, and Yunnan had the highest proportional areas 
$(>60 \%)$ of low-yield cropland. The three provinces of Heilongjiang, Sichuan, and Inner Mongolia had the largest cropland area, but their high-yield areas covered no more than $15 \%$ of the total cropland area.

Table 3 Production capacity and potential promoted productivity of medium-yield cropland in province

\begin{tabular}{|c|c|c|c|c|c|c|}
\hline Province & $\begin{array}{c}\text { Area pro- } \\
\text { portion of } \\
\text { me- } \\
\text { dium-yield } \\
\text { cropland }(\%)\end{array}$ & $\begin{array}{l}\text { Medium-yield } \\
\text { cropland } \\
\text { productivity } \\
\left(\times 10^{4} \mathrm{C}\right)\end{array}$ & $\begin{array}{l}\text { Proportion of } \\
\text { medium-yield } \\
\text { cropland } \\
\text { productivity }(\%)\end{array}$ & $\begin{array}{l}\text { Potential } \\
\text { promoted } \\
\text { productivity } \\
\left(\times 10^{4} \mathrm{C}\right)\end{array}$ & $\begin{array}{l}\text { Increase } \\
\text { rate }(\%)\end{array}$ & $\begin{array}{l}\text { Proportion of } \\
\text { potential pro- } \\
\text { moted produc- } \\
\text { tivity }(\%)\end{array}$ \\
\hline Heilongjiang & 12.53 & 5591.56 & 11.35 & 851.49 & 15.23 & 9.14 \\
\hline Jilin & 4.50 & 2027.35 & 4.12 & 263.31 & 12.99 & 2.83 \\
\hline Liaoning & 4.20 & 1902.89 & 3.86 & 251.32 & 13.21 & 2.70 \\
\hline Beijing & 0.33 & 154.59 & 0.31 & 34.50 & 22.31 & 0.37 \\
\hline Tianjin & 0.50 & 228.52 & 0.46 & 43.74 & 19.14 & 0.47 \\
\hline Hebei & 6.07 & 2731.25 & 5.54 & 552.14 & 20.22 & 5.93 \\
\hline Shandong & 7.06 & 3542.15 & 7.19 & 558.29 & 15.76 & 5.99 \\
\hline Henan & 6.38 & 3368.73 & 6.84 & 440.08 & 13.06 & 4.72 \\
\hline Shanxi & 3.08 & 1272.41 & 2.58 & 282.19 & 22.18 & 3.03 \\
\hline Shaanxi & 2.70 & 1226.67 & 2.49 & 279.82 & 22.81 & 3.00 \\
\hline Gansu & 2.53 & 1046.96 & 2.13 & 303.88 & 29.03 & 3.26 \\
\hline Xinjiang & 2.99 & 1618.20 & 3.28 & 465.51 & 28.77 & 5.00 \\
\hline Inner Mongolia & 5.80 & 2385.04 & 4.84 & 556.47 & 23.33 & 5.97 \\
\hline Ningxia & 0.73 & 284.72 & 0.58 & 99.90 & 35.08 & 1.07 \\
\hline Qinghai & 0.32 & 113.63 & 0.23 & 36.18 & 31.84 & 0.39 \\
\hline Tibet & 0.09 & 30.99 & 0.06 & 13.94 & 44.97 & 0.15 \\
\hline Jiangsu & 3.58 & 1908.20 & 3.87 & 303.91 & 15.93 & 3.26 \\
\hline Anhui & 6.18 & 3316.31 & 6.73 & 519.71 & 15.67 & 5.58 \\
\hline Hubei & 3.60 & 1871.25 & 3.80 & 379.66 & 20.29 & 4.07 \\
\hline Hunan & 2.85 & 1543.79 & 3.13 & 250.27 & 16.21 & 2.69 \\
\hline Jiangxi & 1.90 & 1029.40 & 2.09 & 171.48 & 16.66 & 1.84 \\
\hline Zhejiang & 1.66 & 849.77 & 1.72 & 230.50 & 27.12 & 2.47 \\
\hline Shanghai & 0.35 & 168.73 & 0.34 & 42.25 & 25.04 & 0.45 \\
\hline Guangdong & 2.14 & 1287.21 & 2.61 & 367.70 & 28.57 & 3.95 \\
\hline Guangxi & 2.91 & 1694.63 & 3.44 & 382.28 & 22.56 & 4.10 \\
\hline Fujian & 0.71 & 408.86 & 0.83 & 118.86 & 29.07 & 1.28 \\
\hline Hainan & 0.62 & 445.10 & 0.90 & 139.98 & 31.45 & 1.50 \\
\hline Taiwan & 0.44 & 292.91 & 0.59 & 92.02 & 31.42 & 0.99 \\
\hline Sichuan & 7.30 & 3655.76 & 7.42 & 603.26 & 16.50 & 6.47 \\
\hline Yunnan & 2.29 & 1430.87 & 2.90 & 390.90 & 27.32 & 4.19 \\
\hline Chongqing & 1.88 & 969.52 & 1.97 & 162.34 & 16.74 & 1.74 \\
\hline Guizhou & 1.78 & 865.09 & 1.76 & 130.82 & 15.12 & 1.40 \\
\hline
\end{tabular}

(3) In the case where all medium-yield cropland is improved to high-yield cropland and all low-yield cropland is improved to medium-yield cropland, the productivity of medium- 
and low-yield cropland would increase $19 \%$ and $24 \%$, respectively. The promoted potential of medium-yield cropland productivity was 2.44 times of that of low-yield cropland.

\section{Discussion}

Cropland is classified into seven grades according to cropland quality in the "Distribution of medium- and low-yield cropland and the potential of grain productivity in China (1988)." The seven grades are aggregated into high-, medium-, and low-yield cropland. The areas of high-, medium-, and low-yield cropland account for $32.16 \%, 32.90 \%$, and $34.94 \%$ of the national cropland area, respectively (Lin, 2008). According to the "Cropland resources and their development and utilization in China (1992)," based on the average yield method (Agricultural Natural Resources and Agricultural Regional Planning Institute of Chinese Academy of Agricultural Sciences, 1992; Lin, 2008), the proportional areas of high-, medium-, and low-yield cropland are $21.54 \%, 37.24 \%$, and $41.22 \%$, respectively. Based on the potential productivity method, the area of high-, medium-, and low-yield cropland accounted for approximately $34.92 \%, 41.95 \%$, and $23.14 \%$, respectively. The proportional area of high-, medium-, and low-yield cropland obtained in this study were similar to those of "Cropland resources and their development and utilization in China." However, the proportional area of high-yield cropland was lower than that of the other two methods. The results of each method have the ability to reflect the regional patterns of cropland quality. However, the difference between the previous studies and our study is that, county scale is the smallest spatial unit that can be identified in the previous studies, while a grid detail of $500 \mathrm{~m}$ resolution can be identified in this study.

Faced with limited arable land resources, improving the efficiency of cropland utilization is the only choice for the sustainable development of agriculture and national food security. The detailed spatial patterns of high-, medium-, and low-yield cropland are the basis for a comprehensive improvement of cropland. The notable development of remote sensing technology and ecosystem productivity models made it possible to identify high-, medium-, and low-yield cropland. Remote sensing-based ecosystem productivity models can estimate the spatial patterns of cropland NPP at the grid level and therefore largely improve the spatial precision of high-, medium-, and low-yield cropland distribution relative to traditional county statistics data-based methods. Moreover, remote sensing information can reflect the comprehensive effects of natural conditions and management on crop growth. Based on the cropping system zones of China, high-, medium-, and low-yield cropland are classified under different natural and socio-economic conditions, so cropland quality can be identified region-by-region, rather than classified by a nationwide standard. In this study, cropland productivity was calculated based on 500-m MODIS datasets. To eliminate the effect of mixed pixels on the classification criteria of high-, medium-, and low-yield cropland, the NPP values of pixels with a cropland area proportion of not less than $50 \%$ were used in each agricultural region, and cropland was the major land use type. However, this method is not effective to reduce the uncertainty in those pixels with low proportional areas of cropland. Therefore, productivity data at higher spatial resolutions is required for a more accurate planning of medium- and low-yield cropland improvement. 


\section{References}

Agricultural Natural Resources and Agricultural Regional Planning Institute of Chinese Academy of Agricultural Sciences, National Soil and Fertilizer Station, 1992. Chinese Arable Land Resources and Its Exploitation. Beijing: Surveying and Mapping Press. (in Chinese)

Albrizio R, Steduto P, 2003. Photosynthesis, respiration and conservative carbon use efficiency of four field grown crops. Agricultural and Forest Meteorology, 116(1): 19-36.

Ball J T, 1996. Sensitivity of leaf photosynthesis to $\mathrm{CO}_{2}$ concentration is an invariant function for C3 plants: A test with experimental data and global applications. Global Biogeochemical Cycles, 10(2): 209-222.

Cheng W X, Sims D A, Luo Y et al., 2000. Photosynthesis, respiration, and net primary production of sunflower stands in ambient and elevated atmospheric $\mathrm{CO}_{2}$ concentrations. Global Change Biology, 6(8): 931-941.

Foley J A, DeFries R, Asner G P et al., 2005. Global consequences of land use. Science, 309(5734): $570-574$.

Foley J A, Ramankutty N, Brauman K A et al., 2011. Solutions for a cultivated planet. Nature, 478(7369): $337-342$.

Gifford R M, 1995. Whole plant respiration and photosynthesis of wheat under increased $\mathrm{CO}_{2}$ concentration and temperature: Long-term vs. short-term distinctions for modelling. Global Change Biology, 1(6): 385-396.

Huang M, Ji J J, Peng L L, 2008. The response of vegetation net primary productivity to climate change during 1981-2000 in the Tibetan Plateau. Climatic and Environmental Research, 13(5): 608-617. (in Chinese)

Kalfas J L, Xiao X, Vanegas D X et al., 2011. Modeling gross primary production of irrigated and rain-fed maize using MODIS imagery and $\mathrm{CO}_{2}$ flux tower data. Agricultural and Forest Meteorology, 151(12): 1514-1528.

Li F L, Li B X, Cao W X, 2005. Status and prospect of crop-yield assess by remote sensing. Journal of Yunnan Agricultural University, 5(20): 680-684. (in Chinese)

Lin P S, 2008. Study on the distribution and possible production increase of medium and low-yield farmland in China. Beijing: Chinese Academy of Agricultural Sciences. (in Chinese)

Liu X H, Yang Q k, Tang G A, 2001. Extraction and application of relief of China based on DEM and GIS method. Bulletin of Soil and Water Conservation, 21(1): 57-62.

Shi Q H, Wang H, Chen F et al., 2010. The spatial-temporal distribution characteristics and yield potential of medium-low yielded farmland in China. Chinese Agricultural Science Bulletin, 26(19): 369-373. (in Chinese)

Tilman D, Balzer C, Hill J et al., 2011. Global food demand and the sustainable intensification of agriculture. Proceedings of the National Academy of Sciences, 108(50): 20260-20264.

Wang Y, Huang M, Wang X G, 2010. Impacts of land use and climate change on agricultural productivity in Shanghai. Acta Scientiae Circumstantiae, 30(3): 641-648. (in Chinese)

Wang Z, Xiao X M, Yan X D, 2010. Modeling gross primary production of maize cropland and degraded grassland in northeastern China. Agricultural and Forest Meteorology, 150(9): 1160-1167.

Wu B F, Du X, Meng J H et al., 2009. A remote sensing method to classify high, medium and low yield cropland and its application in Huang-Huai-Hai Basin. Modern Agricultural Development and National Food Security \& Huang-Huai-Hai Modern Agricultural Development Strategy Forum Proceedings, 104-108. (in Chinese)

Xiao X M, Hollinger D, Aber J et al., 2004. Satellite-based modeling of gross primary production in an evergreen needleleaf forest. Remote Sensing of Environment, 89(4): 519-534.

Yan H M, Fu Y L, Xiao X M et al., 2009. Modeling gross primary productivity for winter wheat-maize double cropping system using MODIS time series and $\mathrm{CO}_{2}$ eddy flux tower data. Agriculture, Ecosystems \& Environment, 129(4): 391-400.

Yan H M, Liu J Y, Huang H Q et al., 2012. Impacts of cropland transformation on agricultural production under urbanization and Grain for Green Project in China. Acta Geographica Sinica, 2012, 67(5): 579-588. (in Chinese)

Zhang L, Zhang F G, Jiang G H et al., 2005. Potential improvement of medium low yielded farmland and guarantee of food safety in China. Research of Agricultural Modernization, 26(1): 22-25. (in Chinese)

Zhang W, Li A N, 2012. Study on the optimal scale for calculating the relief amplitude in China based on DEM. Geography and Geo-Information Science, 28(4): 8-12. (in Chinese) 